\title{
Rare sugar D-allose induces specific up-regulation of TXNIP and subsequent G1 cell cycle arrest in hepatocellular carcinoma cells by stabilization of $\mathbf{p} 27^{\mathrm{kip} 1}$
}

\author{
FUMINORI YAMAGUCHI ${ }^{1}$, MAKI TAKATA ${ }^{1,3}$, KAZUYO KAMITORI $^{4}$, MACHIKO NONAKA $^{4}$, \\ YOUYI DONG ${ }^{1}$, LI SUI $^{4}$ and MASAAKI TOKUDA ${ }^{1,2}$

\begin{abstract}
${ }^{1}$ Department of Cell Physiology, Faculty of Medicine, and ${ }^{2}$ The Rare Sugars Research Center, Kagawa University, $1750-1$ Miki-cho, Kita-gun, Kagawa 761-0793; ${ }^{3}$ Teikoku Seiyaku Co. Ltd, 567 Sanbonmatsu, Higashikagawa, Kagawa 769-2695;

${ }^{4}$ Kagawa Industry Support Foundation, 2217-15 Hayashi-cho, Takamatsu, Kagawa 761-0301, Japan
\end{abstract}

Received August 21, 2007; Accepted October 18, 2007

\begin{abstract}
Rare sugars' are defined as monosaccharides that exist in nature but are only present in limited quantities. The development of mass production method of rare sugars revealed some interesting physiological effects of these on animal cells, but the mechanisms have not been well studied. We examined the effect of D-allose on the proliferation of cancer cells and the underlying molecular mechanism of the action. The HuH-7 hepatocellular carcinoma cells were treated with various monosaccharides for $48 \mathrm{~h}$ and D-allose was shown to inhibit cell growth by $40 \%$ in a dose-dependent manner. D-allose induced G1 cell cycle arrest but not apoptosis. The microarray analysis revealed that D-allose significantly up-regulated thioredoxin interacting protein (TXNIP) gene expression, which is often suppressed in tumor cells and Western blot analysis confirmed its increase at protein level. The overexpression of TXNIP also induced G1 cell cycle arrest. Analysis of cell cycle regulatory genes showed p27kip1, a key regulator of G1/S cell cycle transition, to be increased at the protein but not the transcriptional level. Protein interaction between TXNIP and jab1, and p27kip1 and jab1, was observed, suggesting stabilization of p27kip1 protein by the competitive inhibition of jab1-mediated nuclear export of $\mathrm{p} 27^{\mathrm{kip} 1}$ by TXNIP. In addition, increased interaction and nuclear localization of TXNIP and p27 kipl were apparent after D-allose treatment. Our findings surprisingly suggest that D-allose, a simple monosaccharide, may act as a novel anticancer agent via unique TXNIP induction and p27kip1 protein stabilization.
\end{abstract}

Correspondence to: Dr Masaaki Tokuda, Department of Cell Physiology, Faculty of Medicine, Kagawa University, 1750-1, Ikenobe, Miki-cho, Kita-gun, Kagawa 761-0793, Japan

E-mail: tokuda@med.kagawa-u.ac.jp

Key words: D-allose, rare sugar, cell cycle, TXNIP, p27kip1

\section{Introduction}

'Rare sugars' are defined as monosaccharides that exist in nature but are only present in limited quantities. There are more than 50 kinds of rare sugars while naturally abundant monosaccharides such as D-glucose and D-fructose are very few in number. Recently, Izumori et al developed a simple method to convert D-fructose to D-psicose by D-tagatose 3-epimerase and D-psicose to D-allose by L-rhamnose isomerase (Fig. 1A), facilitating studies of the effects of these rare sugars in animals (1). Among the rare sugars, D-psicose and D-allose showed strong scavenging activity toward reactive oxygen species compared with D-glucose and D-fructose, and D-allose inhibited the production of reactive oxygen from neutrophils (2). D-allose also improved the microcirculation on hepatic ischemia reperfusion (3). Sui et al reported that D-allose inhibited the proliferation of some cancer cell lines $(4,5)$, but the underlying mechanisms have remained completely unknown. In this study, we showed that D-allose inhibited cancer cell growth specifically without affecting normal cells and revealed the detail of its molecular mechanism of action via the TXNIP induction.

\section{Materials and methods}

Materials. Sugars used in this study including D-glucose, D-fructose, D-psicose, D-allose, D-altrose, D-galactose, D-gulose and D-mannose were supplied by The Rare Sugars Research Center, Kagawa University, Kagawa, Japan.

Cell culture. Human hepatocellular carcinoma (HuH-7) cell line was purchased from the Japanese Cancer Research Resources Bank and maintained at $37^{\circ} \mathrm{C}$ under a humidified atmosphere of $5 \% \mathrm{CO}_{2}$ in DMEM (Sigma) supplemented with $10 \%(\mathrm{v} / \mathrm{v})$ fetal bovine serum and $1 \%$ penicillinstreptomycin (GE Healthcare). Normal rat hepatocytes were purchased from the Cell Applications Inc. (San Diego, CA). Cells were maintained on the collagen coated dish in the rat hepatocyte maintenance medium (provided with the kit). 
A

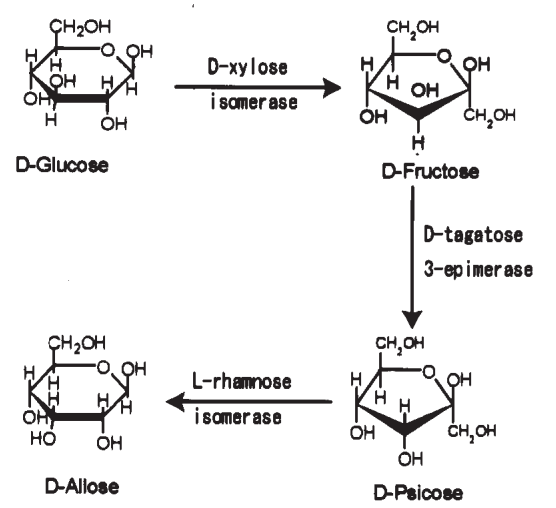

C

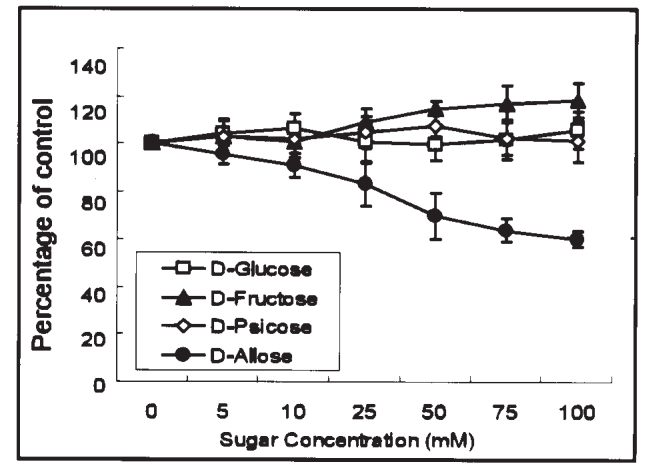

B

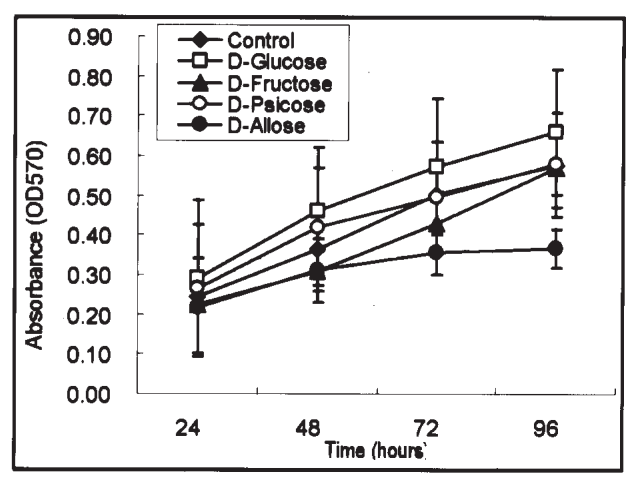

D

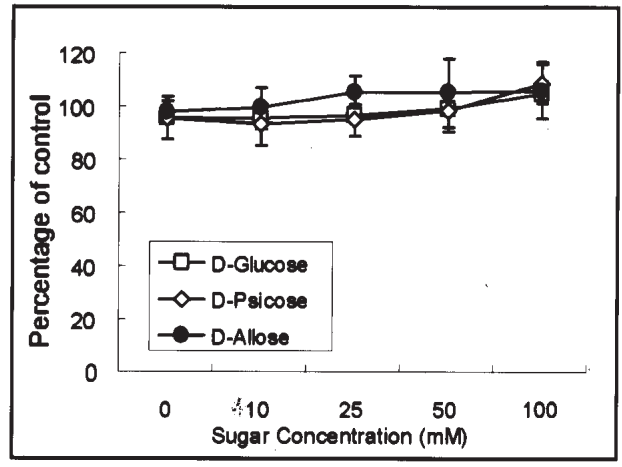

Figure 1. Structures of rare sugars and their effects on the cell growth. (A) D-psicose was converted from D-fructose by the D-tagatose 3-epimerase and further treatment of D-psicose with the L-rhamnose isomerase produced D-allose. (B) HuH-7 cells were treated with 50 mM of various sugars and cell growth was measured by the MTT method. Data shown are mean \pm SD values $(n=3-4)$. (C) Various concentrations of sugars were added and cell growth was measured by the MTT method after $48 \mathrm{~h}$. Data shown are mean \pm SD values (n=6-11). (D) Normal rat primary hepatocytes were treated with 50 mM of sugars for $48 \mathrm{~h}$ and cell growth was measured by the MTT method. Data are mean \pm SD values $(\mathrm{n}=3)$.

Construction of expression vector and transfection. The full-length human TXNIP, p27 ${ }^{\mathrm{kip} 1}$ and jab1 cDNA were amplified from normal human liver total RNA (Clontech) using specific primers. The TXNIP cDNA was subcloned into pAcGFP1-N1 (Clontech) or pME18s-FLAG mammalian expression vector (6). The human $\mathrm{p} 27^{\mathrm{kip} 1} \mathrm{cDNA}$ was subcloned into pCMV-Myc mammalian expression vector (Clontech) and jab1 cDNA was subcloned into pEF4/V5-His mammalian expression vector (Invitrogen), and confirmed by sequencing. Constructs were transfected into the HuH-7 cells with Fugene- 6 transfection reagent (Roche) following the manufacturer's protocol.

Cell growth assay. HuH-7 cells were grown in 96-well plates at 7,500 cells/well in $0.1 \mathrm{ml}$ medium and cultured for $24 \mathrm{~h}$. Sugars were added to the medium and the cells were further cultured up to $96 \mathrm{~h}$. Proliferation was measured using the 3-(4,5-dimethyl-thiazol-2-yl)-2, 5-diphenyltetrazolium bromide (MTT) method and relative cell growth was expressed as a percentage of the value for untreated control cultures. For the normal rat hepatocytes assay, 96-well plates were coated with a rat collagen and 30,000 cells/well were seeded. The cells were cultured for $24 \mathrm{~h}$ and various concentrations of D-allose, D-psicose, or D-glucose were added to the medium. The cells were further cultured for $48 \mathrm{~h}$ and processed for MTT assay.
Cell cycle analysis. Cells were cultured with D-allose and harvested by trypsinization, washed twice with ice-cold PBS and fixed in $70 \%$ ethanol for $2 \mathrm{~h}$ at $4^{\circ} \mathrm{C}$. After washing with PBS and incubation in PBS containing $50 \mu \mathrm{g} / \mathrm{ml}$ propidium iodide (Wako) and $200 \mu \mathrm{g} / \mathrm{ml}$ RNAse A (Sigma) for $30 \mathrm{~min}$, flow cytometric analysis was preformed with a FACSEpics XL flow cytometer (Beckman Coulter). To examine the effect of TXNIP overexpression, cells were transfected with the human TXNIP cDNA cloned into the pAcGFP1-N1 expression vector (Clontech) using the Fugene-6 transfection reagent (Roche). Only transfected cells were sorted and processed for analysis. Effects on the cell cycle were determined with reference to changes in the percentage cell distribution in each phase of the cell cycle and analyzed using System II software (Beckman Coulter). As a control, the expression vector without TXNIP cDNA was used.

cDNA microarray analysis. Total RNA was isolated from HuH-7 cells treated with or without $50 \mathrm{mM} \mathrm{D-allose} \mathrm{for} 48 \mathrm{~h}$ using RNeasy mini kit (Qiagen). Five microgram of each sample was converted to cRNA and labeled with Cyanine 5or Cyanine 3-CTP using Agilent low linear amplification kit. Each probe was denatured and hybridized to the Agilent human oligo microarray for $17 \mathrm{~h}$ at $65^{\circ} \mathrm{C}$. The array was washed with 6 X SSPE, $0.005 \% \mathrm{~N}$-Lauroylsarcosine for $1 \mathrm{~min}$, 
then $0.06 \mathrm{X}$ SSPE, $0.005 \% \mathrm{~N}$-Lauroylsarcosine for $1 \mathrm{~min}$ at room temperature. The array was immersed into the Agilent Stabilization and Drying Solution for $30 \mathrm{sec}$ and dried. The fluorescent signal was scanned using the Agilent microarray scanner and the intensity of signal was analyzed by the feature extraction software (Agilent). The experiment was replicated using different set of samples and data were analyzed with the NIA array analysis software (7). The statistical significance was determined using ANOVA with the False Discovery Rate $(F D R)$ method $(\mathrm{P}<0.05)$ proposed by Benjamini and Hochberg (8). Genes were classified using the Database for Annotation, Visualization and Integration Discovery (DAVID 2.1) (9).

Real-time quantitative PCR. The HuH-7 cells were cultured in 24-well plates and $50 \mathrm{mM}$ of various sugars were added to the medium and further incubated. Total RNA was purified and used to synthesize cDNAs with random hexamers. Real-time quantitative PCR was carried out using a Taqman gene expression assay primers and the 7300 real-time PCR system (Applied Biosystems). Each reaction was performed in duplicate. The $B$-actin gene was used to normalize across assay and runs and the threshold value $(\mathrm{Ct})$ for each sample was used to determine the expression level of the gene.

Western blotting and immunoprecipitation analysis. After sugar treatment, cells were scraped into a lysis buffer $(20 \mathrm{mM}$ Tris- $\mathrm{HCl}, \mathrm{pH} 7.5,150 \mathrm{mM} \mathrm{NaCl}, 5 \mathrm{mM}$ EDTA, $0.5 \%$ Triton$\mathrm{X}-100,0.5 \% \mathrm{NP} 40$ ) with protease inhibitors and treated with sonication. Samples were centrifuged for $10 \mathrm{~min}$ at $14,000 \mathrm{rpm}$ and the supernatant was collected. For Western blot analysis, proteins were separated in $10 \%$ SDS-PAGE gels, transferred to nitrocellulose membranes blocked with $5 \%(\mathrm{w} / \mathrm{v})$ non-fat dried milk in TTBS and incubated with anti-flag (Sigma), anti-myc and anti-V5 (Invitrogen), antiTXNIP, anti-p27 $7^{\text {kip } 1}$, anti-p2 $1^{\text {waf1/cip } 1}$, anti-p53, anti-Cdk2, anti-Cdk4, anti-cyclin D1, and anti-cyclin E (MBL), or antiB-actin antibodies (Sigma). Membranes were probed with a horseradish peroxidase-conjugated anti-rabbit or anti-mouse IgG (Amersham), and signals were detected with an enhanced chemiluminescence system (Amersham). For immunoprecipitation analysis, proteins were incubated with antiFLAG M2 agarose (Sigma), anti-V5 agarose (Invitrogen) or anti-myc agarose (Invitrogen) and incubated for $2 \mathrm{~h}$ at $4^{\circ} \mathrm{C}$. Samples were washed with $0.1 \%$ Triton X-100 in TBS and subjected to Western blot analysis.

Immunohistochemistry. Cells were cultured on glass slides and transfected with flag-TXNIP and myc-p27kip1 plasmid. After transfection, these cells were further cultured with or without $50 \mathrm{mM}$ D-allose. They were fixed in $4 \%$ paraformaldehyde in PBS for $30 \mathrm{~min}$ before treatment with cold acetone/methanol for 2 min and blocking with a blocking buffer (3\% BSA, 3\% goat serum, and $0.1 \%$ TritonX-100 in $\mathrm{PBS}$ ) for $1 \mathrm{~h}$ at room temperature. Samples were then incubated with anti-TXNIP or with anti-p27kip1 antibodies overnight at $4{ }^{\circ} \mathrm{C}$, then with Alexa Flour 488 or Alexa Flour 594 antibodies (Molecular Probes) for $1 \mathrm{~h}$. Signals were observed under an LSM-GB200 confocal laser scanning microscope (Olympus).

\section{Results}

Cell growth assay. The effect of rare sugars on HuH-7 cell growth was assayed by the MTT method. D-glucose, D-fructose and D-psicose did not show any growth inhibitory effects compared with control (no sugar addition), but D-allose significantly suppressed cell growth after $96 \mathrm{~h}$ $(n=3-4)$ (Fig. 1B). This effect was dose-dependent and was observed from $5 \mathrm{mM}$ (n=6-11) (Fig. 1C). Rat hepatic primary culture cells were also treated with D-glucose, D-psicose or $\mathrm{D}$-allose to examine whether the growth inhibition by $\mathrm{D}$-allose is specific to the cancer cell line. No growth inhibitory or cytotoxic effects were observed in the normal cells up to $100 \mathrm{mM}$ of sugars tested (Fig. 1D).

Cell cycle analysis. Cells were cultured with or without $50 \mathrm{mM}$ D-allose for $96 \mathrm{~h}$, were harvested and nuclei were stained with propidium iodide. The percentage of cells in each cell cycle phase was analyzed with flow cytometry (Fig. 2A). Without D-allose treatment, $59.0 \pm 1.1 \%$ of cells were in $\mathrm{G} 1$ phase and D-allose significantly increased this to $63.7 \pm 1.1 \%$ $(\mathrm{p}<0.05, \mathrm{n}=4$ each). The percentage in $\mathrm{S}$ phase decreased from $28.1 \pm 1.2 \%$ without $D$-allose to $24.6 \pm 1.3 \%$ ( $n=4$ each) with D-allose treatment. These observations suggested that D-allose inhibits the HuH-7 cell growth by inducing the G1 cell cycle arrest.

Western blot analysis of cell cycle regulatory proteins. The expression of cell cycle regulatory proteins was analyzed by Western blot after 48 and $96 \mathrm{~h}$ of D-allose treatment. The level of cyclin D1, cyclin E and Cdk4 was not changed, whereas the expression of Cdk2 increased after 48 and $96 \mathrm{~h}$ of D-allose treatment (Fig. 2B). The expression of $\mathrm{p} 21^{\text {waf } 1 / \mathrm{cip} 1}$ and p53 also showed no clear alteration. The level of the p2 $7^{\mathrm{kip} 1}$ protein was increased after $96 \mathrm{~h}$ both in the presence and absence of D-allose and the extent of the increase with D-allose was significantly greater than without treatment.

Gene expression analysis. The gene expression profiles of HuH-7 cells with or without D-allose treatment was compared by a microarray technique. Approximately 20,000 human genes were analyzed. The experiment was replicated using different set of samples and the statistical significance was determined using ANOVA with the False Discovery Rate (FDR) method $(\mathrm{P}<0.05)$. Genes showing $>3$-fold changes were listed and these genes were classified using the Database for Annotation, Visualization and Integration Discovery (DAVID 2.1) in Table I. There were 37 upregulated and 11 down-regulated genes observed. Among the up-regulated genes, the expression of the TXNIP was most significantly increased $>10$-fold). This gene has not been functionally classified, but was reported as a tumor suppressor (10) or metastasis suppressor gene (11). Regarding the cell cycle regulation, the expression of cyclin-dependent kinase inhibitor 2B (CDKN2B) was increased, whereas FK506 binding protein 12-rapamycin associated protein 1 (FRAP1) was decreased. For the transcriptional regulation, homeobox B8 (HOXB8), paired box protein (PAX2) and Tcell acute lymphocytic leukemia 1 (TAL1) was up-regulated and glial cells missing homolog 1 (GCM1) and cofactor 
Table I. Gene expression profile of HuH-7 cells after D-allose treatment.

\begin{tabular}{l} 
Accession no. \\
\hline Unknown \\
NM_006472 \\
Cell cycle \\
NM_004936 \\
NM_004958 \\
Transcriptional regulation \\
NM_003189 \\
NM_003643 \\
NM_004830 \\
L25597 \\
NM_024016
\end{tabular}

Gene name

Fold change

Signal transducer activity

NM_033179

Thioredoxin interacting protein (TXNIP)

10.5

Cyclin-dependent kinase inhibitor 2B (pl5, inhibits CDK4)

3.95

(CDKN2B), transcript variant 1

FK506 binding protein 12-rapamycin associated protein 1 (FRAP1)

T-cell acute lymphocytic leukemia 1 (TALI)

3.01

Glial cells missing homolog 1 (Drosophila) (GCM1)

Cofactor required for $\mathrm{Spl}$ transcriptional activation,

subunit 3, $130 \mathrm{kDa}$ (CRSP3), transcript variant 1

Paired box protein mRNA, complete cds

Homeobox B8 (HOXB8)

NM_001048

Olfactory receptor, family 51, subfamily B, member 4 (OR51B4)

NM_172234

Somatostatin (SST)

NM_001001923

Interleukin 17 receptor B (IL17RB), transcript variant 2

$-3.63$

Olfactory receptor, family 5, subfamily C, member 1 (OR5C1) 3.09

NM_004054

Complement component 3a receptor 1 (C3AR1)

$-3.37$

NM_000684

Adrenergic, $3-1-$, receptor (ADRB1)

NM_144720

Janus kinase and microtubule interacting protein 1 (JAKMIP1)

NM_005586

MyoD family inhibitor (MDFI)

NM_021186

Zona pellucida glycoprotein 4 (ZP4)

Transporter activity

NM_001045

NM_012283

NM_003044

NM_001170

NM_006514

Solute carrier family 6 (neurotransmitter transporter,

serotonin), member 4 (SLC6A4)

Potassium voltage-gated channel, subfamily G,

member 2 (KCNG2)

Solute carrier family 6 (neurotransmitter transporter,

betaine/GABA), member 12 (SLC6A12)

Aquaporin 7 (AQP7)

Sodium channel, voltage-gated, type $\mathrm{X}, \alpha$ (SCN10A)

Ion binding

NM_019855

NM_178125

NM_033386

NM_199293

NM_014677

NM_207660

Calcium binding protein 5 (CABP5)

Tripartite motif-containing 50 (TRIM50)

MICAL-like 1 (MICAL-L1)

Tyrosine hydroxylase (TH), transcript variant 3

Zinc finger CCCH-type containing 14 (ZC3H14), transcript variant 2

Nucleotide binding

NM_002688

NM_007054

NM_144583

Septin 5 (SEPT5)

Kinesin family member 3A (KIF3A)

ATPase, $\mathrm{H}+$ transporting, lysosomal $42 \mathrm{kDa}$,

Catalytic activity

NM_007180

VI subunit C2 (ATP6V1C2), transcript variant 2

NM_032385

Trehalase (brush-border membrane glycoprotein) (TREH)

Chromosome 5 open reading frame 4 (C5orf4), transcript variant $2 \quad 3.33$

NM_018245

Oxoglutarate dehydrogenase-like (OGDHL) 
Table I. Continued.

\begin{tabular}{llc}
\hline Accession no. & \multicolumn{1}{c}{ Gene name } & Fold change \\
\hline NM_001040 & Sex hormone-binding globulin (SHBG) & -3.79 \\
NM_006033 & Lipase, endothelial (LIPG) & -3.87 \\
Structural molecule activity & & 3.20 \\
NM_000394 & Crystalin, a A (CRYAA) \\
NM_015719 & Collagen, type V, $\alpha$ 3 (COL5A3) \\
Others & & 3.28 \\
NM_033377 & & 3.81 \\
NM_001012276 & Chorionic gonadotropin, B polypeptide 1 (CGB1) \\
NM_016651 & PRAME family member 8 (PRAMEF8) \\
NM_001882 & Dapper, antagonist of B-catenin, homolog 1 (DACT1) \\
NM_012288 & Corticotropin releasing hormone binding protein (CRHBP) \\
NM_203376 & Translocation associated membrane protein 2 (TRAM2) & 3.58 \\
NM_013364 & Transmembrane protein 81 (TMEM81) \\
NM_024770 & Paraneoplastic antigen MA3 (PNMA3) \\
NM_012109 & Methyltransferase like 8 (METTL8) \\
NM_145172 & Chromosome 19 open reading frame 4 (C19orf4) \\
NM_001012361 & WD repeat domain 63 (WDR63) \\
\hline
\end{tabular}

Values are ratios of gene expression levels from D-allose treated cells over control. Microarray experiments were replicated using different sets of samples and the statisticals significance of data was analysed using Anova with the Benjamin and Hochberg False Discovery Rate (FDR) method $(\mathrm{P}<0.05)$. Genes up- or down-regulated more than 3-fold were listed and classified using the Database for Annotation, Visualization and Integration Discovery (DAVID 21.1). Genes classified in an ontology group containing a few genes are not listed.

A
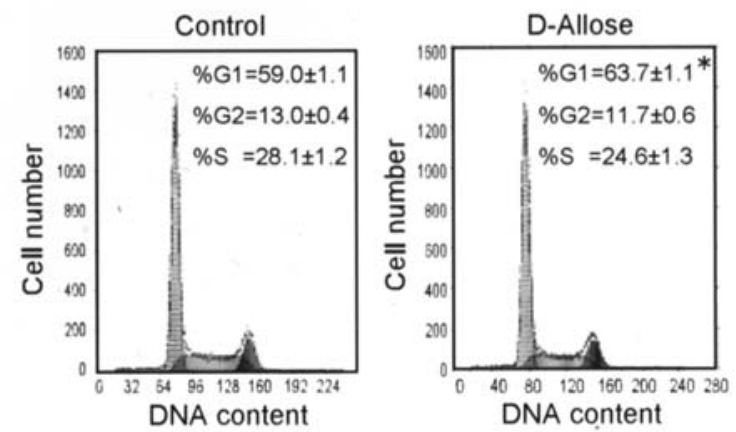

B

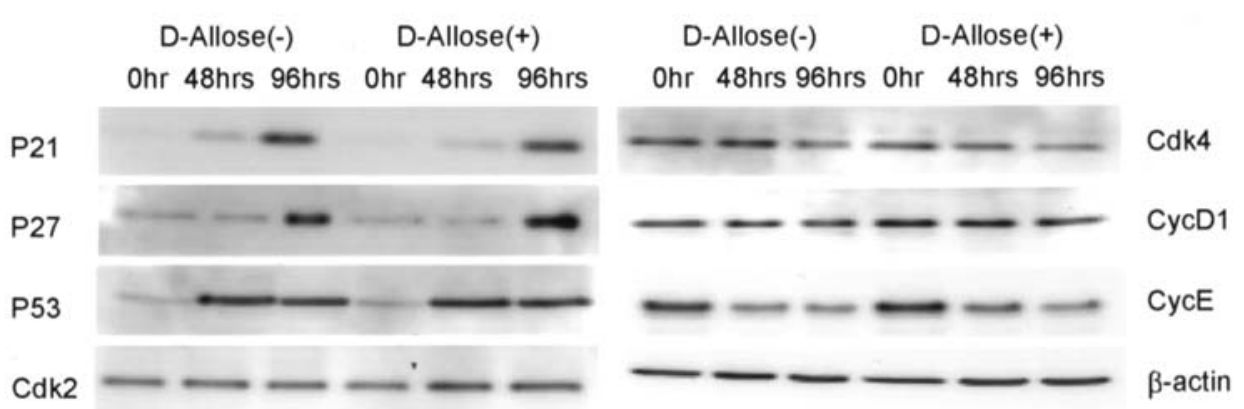

Figure 2. Cell cycle analysis of the HuH-7 cells with or without D-allose. (A) Cells were cultured with or without $50 \mathrm{mM} \mathrm{D}$-allose for $96 \mathrm{~h}$ and analyzed by flow cytometry. Data are mean \pm SD values. ${ }^{~} \mathrm{P}<0.05$ by Fisher's PLSD analysis $(\mathrm{n}=4)$. (B) Western blot analysis of cell cycle regulatory proteins. 0,48 and $96 \mathrm{~h}$ samples with or without $50 \mathrm{mM}$ D-allose treatment were separated by SDS-PAGE and Western blotting was performed with the indicated antibodies. 
A

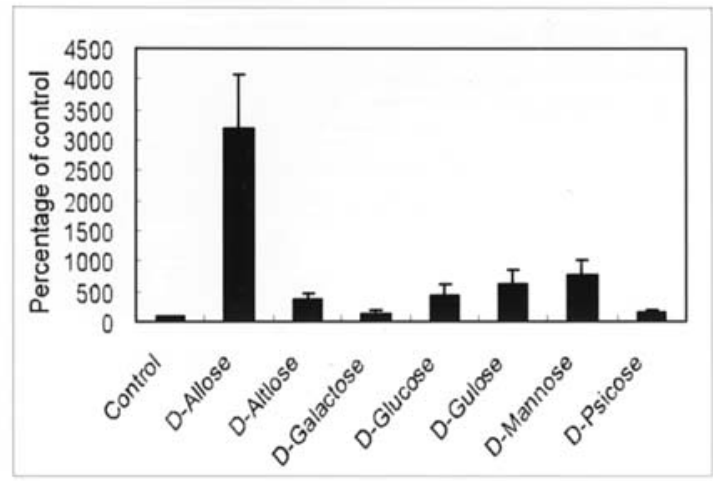

C

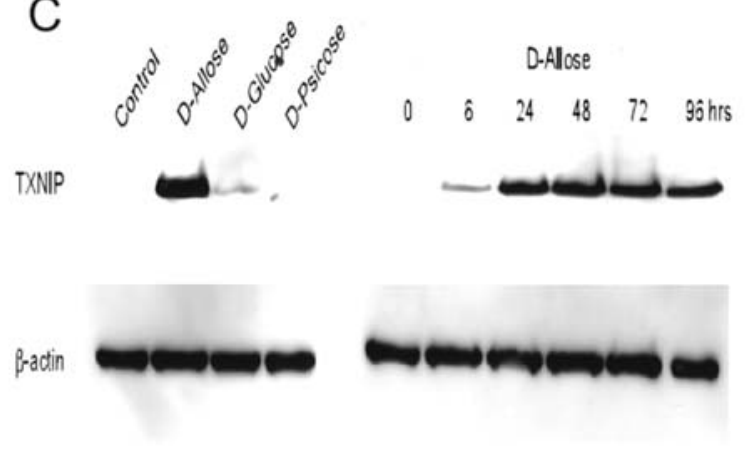

B
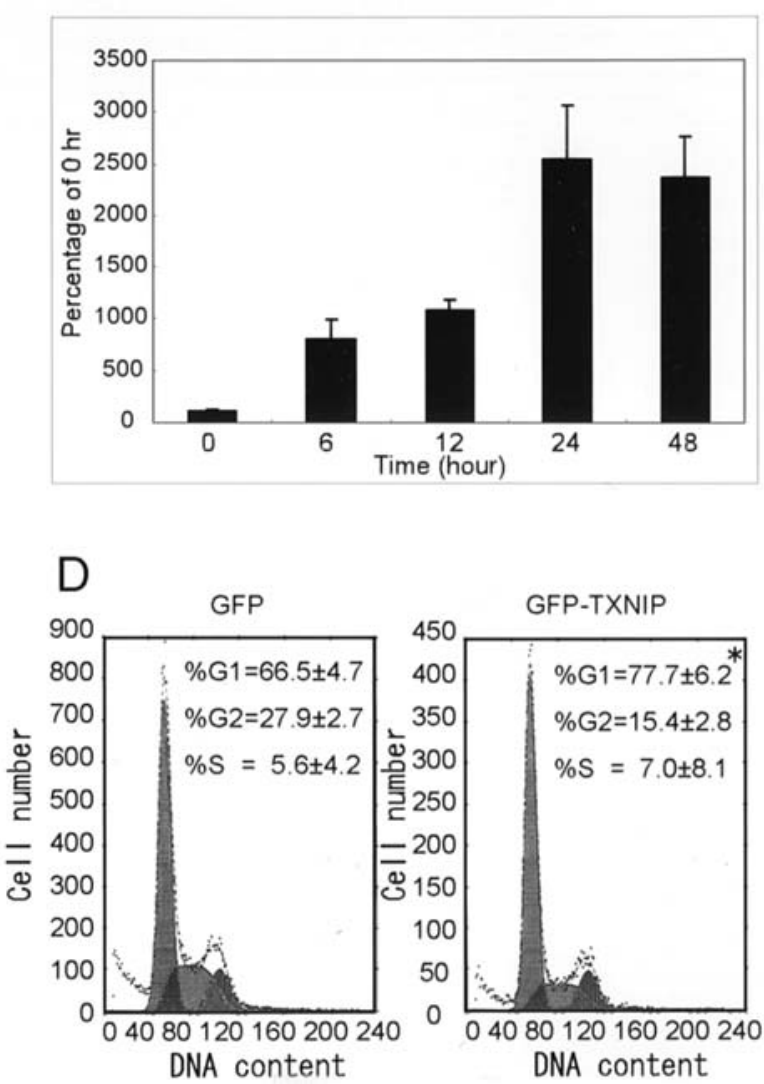

Figure 3. TXNIP induction by various sugars and its association with cell cycle arrest. (A) HuH-7 cells were treated with 50 mM of each sugar for 48 h. Total RNA was extracted and used for real-time PCR. Data are mean \pm SD values $(n=4)$. (B) Time course analysis of TXNIP mRNA expression after 50 mM D-allose treatment. Data are mean \pm SD values $(n=3-6)$. (C) Western blot analysis of TXNIP. Left panel, sugars were added to the medium of HuH-7 cells and cells were incubated for $48 \mathrm{~h}$. Total proteins were used for Western blot analysis. Right panel, time course of TXNIP protein levels assessed by Western blot analysis. (D) Cell cycle analysis of GFP (as control) or GFP-TXNIP overexpressing HuH-7 cells. Cells were transfected with GFP or GFP-TXNIP expression vector and only transfected cells were sorted and analyzed by flow cytometry. Data are mean \pm SD values. ${ }^{*} \mathrm{P}<0.05$ by Fisher's PLSD analysis ( $\mathrm{n}=5$ ).

required for Sp1 transcriptional activation, subunit 3,130 kDa (CRSP3), transcript variant 1 were down-regulated. D-allose treatment also regulated other genes $(5$ genes in transporter activity, 9 genes in signal transducer activity, 6 genes in ion binding, 3 genes in nucleotide binding, 5 genes in catalytic activity and 2 genes in structural molecule activity). Eight genes were not classified.

Real-time PCR and Western blot analysis of TXNIP. Based on the result of the microarray analysis, we evaluated the expression of TXNIP by real-time PCR. Various sugars were applied to the HuH-7 cells and cells were incubated for $48 \mathrm{~h}$ and the levels of TXNIP induction was compared (Fig. 3A). The D-allose treatment markedly elevated TXNIP expression about 30-fold, although some other sugars including D-mannose, D-gulose and D-glucose also showed a several-fold induction $(n=4)$. The induction of TXNIP by D-allose was already observed after $6 \mathrm{~h}(\mathrm{n}=3-6)$ (Fig. 3B). Protein levels of TXNIP were also studied by Western blot (Fig. 3C). The expression of TXNIP was compared after sugar treatment. TXNIP protein level was significantly increased by $\mathrm{D}$-allose and to a lesser extent by D-glucose treatment (Fig. 3C). The time course of TXNIP protein level after $\mathrm{D}$-allose treatment revealed that the increase of protein was observed after $6 \mathrm{~h}$ and kept at high level until $96 \mathrm{~h}$.
Effect of TXNIP overexpression on cell cycle. The effect of TXNIP overexpression in HuH-7 cells was examined by constructing a GFP-TXNIP fusion protein expression vector and transfection into $\mathrm{HuH}-7$ cells. After transfection of GFP-TXNIP or GFP expression vector (control), cells were harvested and nuclei were stained with propidium iodide. The cells were sorted by the fluorescence of GFP protein to collect the transfected cells only and the percentage of cells in each cell cycle phase was analyzed (Fig. 3D). An increase in the percentage of $\mathrm{G} 1$ phase cells was observed in the cells expressing GFP-TXNIP protein compared to that of GFP protein $[77.7 \pm 6.2 \%$ and $66.5 \pm 4.7 \%$, respectively $(\mathrm{p}<0.05, \mathrm{n}=5$ each $)]$.

Immunoprecipitation analysis. To study the molecular mechanism of cell cycle regulation by TXNIP induced by D-allose, the interaction of TXNIP and other interacting proteins, p27 kipl and jab1, was evaluated. The flag-TXNIP, myc-p27 kip1 and V5-jab1 plasmid were co-transfected into HuH-7 cells and immunoprecipitation and Western blot analysis were performed. Interactions between TXNIP and jab1, and between p27 ${ }^{\mathrm{kip} 1}$ and jab1 were observed (Fig. 4A). In addition, D-allose enhanced the interaction of TXNIP and $27^{\mathrm{kip} 1}$, although absolute amounts of the proteins were not significantly altered (Fig. 4B). 
A

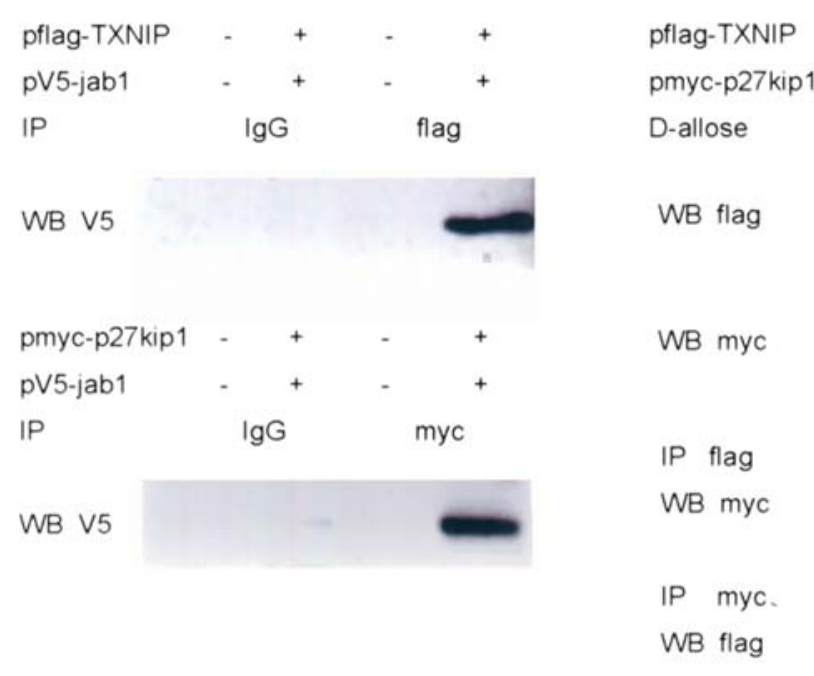

B

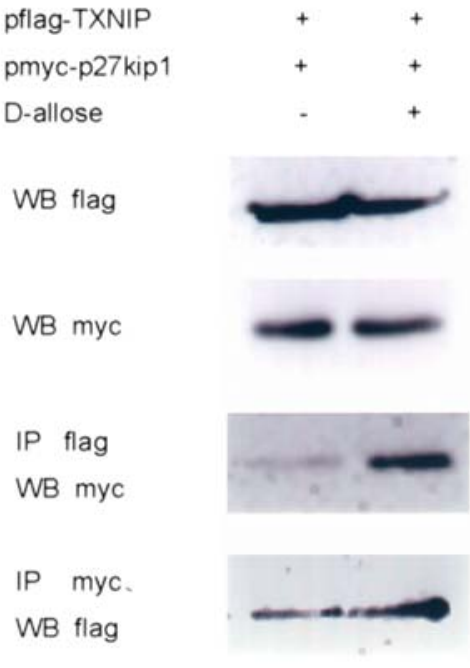

C
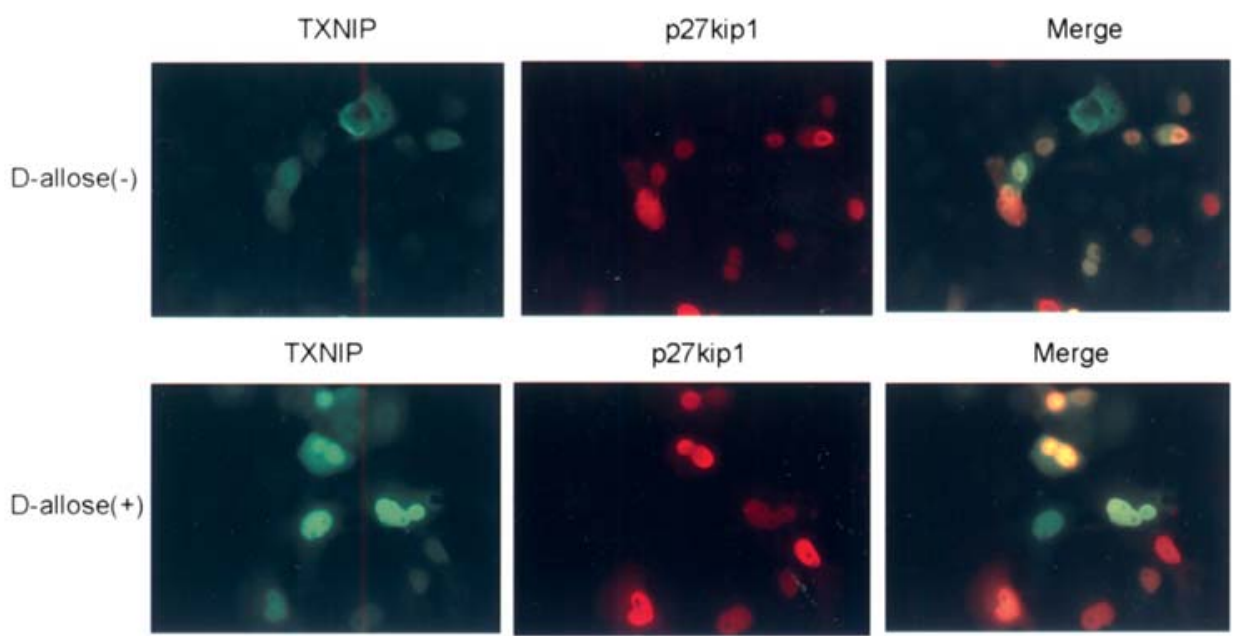

Figure 4. Interaction and localization of TXNIP, p2 $7^{\mathrm{kip} 1}$ and jab1 proteins. (A) Flag-tagged TXNIP and V5-tagged jab1 or myc-tagged p27kip and V5-tagged jab1 plasmid were co-transfected and proteins were immunoprecipitated with either anti-flag or anti-myc agarose. Normal IgG was used as a control. Samples were separated on $10 \%$ SDS-PAGE and Western blotting was performed with anti-V5 antibodies. (B) Flag-tagged TXNIP and myc-tagged p27kipl plasmid were co-transfected and cells were cultured with or without $50 \mathrm{mM} \mathrm{D}$-allose for $48 \mathrm{~h}$. Total protein was used for Western blotting with anti-flag or anti-myc antibodies. Immunoprecipitation was also performed with anti-flag or anti-myc agarose, and Western blot analysis was carried out with anti-myc or anti-flag antibodies, respectively. (C) Immunohistochemical analysis of TXNIP and p27 kipl with or without D-allose treatment. Flag-tagged TXNIP and myc-tagged p2 $7^{\mathrm{kip} 1}$ were cotransfected in HuH-7 cells and treated with or without D-allose. Signal was examined with a confocal laser scanning microscope.

Immunohistochemical analysis. The localization of TXNIP and $\mathrm{p} 27^{\mathrm{kip} 1}$ protein was examined by immunohistochemical study. Cells were cultured on glass slides and transfected with TXNIP and $\mathrm{p} 27^{\mathrm{kip} 1}$ plasmid before treatment with or without $50 \mathrm{mM}$ D-allose. The localization of these proteins was visualized with anti-TXNIP or with anti-p2 $7^{\mathrm{kip} 1}$ antibodies followed by fluorescent antibodies. The result demonstrated that overexpressed TXNIP protein was localized mainly in the cytoplasm without D-allose treatment, while p27 ${ }^{\text {kip } 1}$ was apparent in both the cytoplasm and nucleus (Fig. 4C). However, both proteins were predominantly located in the nucleus after D-allose exposure.

\section{Discussion}

The HuH-7 cell growth inhibition was observed by D-allose from $5 \mathrm{mM}$ and is specific to the cancer cells as there was no growth inhibitory or cytotoxic effect on the normal liver cells (Fig. 1D). D-allose inhibited the cell growth by inducing the cell cycle arrest. Compared with the control, D-allose increased the percentage of cells in G1 phase (Fig. 2A). The Western blot analysis showed significant increase of p27kip1 protein by D-allose compared to control (Fig. 2B). Cell cycle progression is tightly regulated by regulatory proteins including cyclins, cyclin-dependent kinases (Cdks) and Cdk inhibitors $(12,13)$. Since p2 $7^{\mathrm{kip} 1}$ is a key regulator of the 
G1 cell cycle progression (14), the result indicated that $\mathrm{D}$-allose causes $\mathrm{G} 1$ cell cycle arrest by modulating the level of the p $27^{\mathrm{kip} 1}$ protein. On the other hand, no apoptotic change by D-allose was observed (data not shown).

To analyze the molecular mechanism in detail, we performed gene expression analysis by the microarray technique. Genes showing $>3$-fold change are listed in Table I. There were 37 up-regulated and 11 down-regulated genes. Among these, the TXNIP expression was most significantly up-regulated (10.5-fold). This gene was originally cloned as a vitamin D3 up-regulated protein (VDUP1) after 1,25-dihydroxyvitamin D3 treatment of HL-60 cells (15). TXNIP is known to interact with thioredoxin and is involved in the regulation of the redox state of cells (16). This gene is also known as a tumor suppressor (10) or metastasis suppressor (11), and its expression is lower in cancer, including colorectal, gastric and breast cancers, than in normal cells $(17,18)$. This might explain why D-allose inhibits growth of cancer cells effectively without affecting normal cells via TXNIP induction (Fig. 1B and D). In addition, TXNIPdeficient mice show an increased incidence of hepatocellular carcinoma (19), indicating that TXNIP expression is important for the suppression of abnormal cell proliferation such as cancers. In this study, the overexpression of TXNIP caused G1 cell cycle arrest in HuH-7 cells (Fig. 3D). This result supported the idea that the up-regulated TXNIP by D-allose is a key factor for growth inhibition. We compared the TXNIP induction by different sugars and it was more significant by D-allose than other sugars tested (Fig. 3A). The increase of TXNIP was observed after $6 \mathrm{~h}$ of D-allose treatment (Fig. 3B and C). There was also slight increase of TXNIP expression by D-mannose, D-gulose, D-glucose and D-altrose. The induction of TXNIP by D-glucose was reported in islet cells (20) or with 2-deoxy-D-glucose and 3O-methylglucose in the pancreatic beta-cell line INS-1 (21). The mechanism of TXNIP induction by D-allose is not clear, but D-glucose stimulation of TXNIP induction through a carbohydrate response element was reported $(20,21)$. As the structures of D-glucose and D-allose are similar (Fig. 1A), induction by $\mathrm{D}$-allose might be via the similar mechanism, but further investigations are necessary. The microarray analysis showed up-regulation of CDKN2B and downregulation of FRAP1 (Table I). CDKN2B is one of the CDK inhibitors and controls the G1 cell cycle progression. The FRAP1 has serine/threonine kinase activity and promotes G1 phase progression through signaling to p70/S6 kinase and 4EBP1 (properties of heat and acid stability/eukaryotic initiation factor 4E-binding protein) (22). The increase of CDKN2B and decrease of FRAP1 expression may also contribute the growth inhibitory effect of D-allose.

Regarding the cell cycle regulatory protein, the increase of the $\mathrm{p} 27^{\mathrm{kip} 1}$ protein by D-allose was observed without any transcriptional induction (data not shown), indicating possible enhancement of protein stability. Nuclear p $27^{\mathrm{kip} 1}$ is generally exported to the cytoplasm for ubiquitination and degraded by the $26 \mathrm{~S}$ proteosome (23). Interestingly, increased rates of proteosome mediated degradation suppress protein levels of p27 kip 1 in cancer cells (24). Nuclear export of p27 kip1 is known to be mediated by the jab1 (25), originally identified as a co-activator of c-jun and junD (26), incorporated into the
COP9 signalosome involved in modulation of gene transcription, signal transduction and protein stability (23). TXNIP is reported to interact with the jab1 competitively and inhibit p27 ${ }^{\mathrm{kip} 1}$ transport, resulting in increased protein levels (27). The immunoprecipitation study confirmed the interaction between TXNIP and jab1, and between p27 ${ }^{\text {kip1 }}$ and jab1 (Fig. 4A). These findings support the work of other research groups $(25,27)$. In addition, we report the first observation of the direct interaction between TXNIP and p27 ${ }^{\mathrm{kip} 1}$ which was significantly enhanced after D-allose treatment (Fig. 4B). The immunohistochemical study showed that overexpressed TXNIP protein was localized mainly in the cytoplasm without D-allose, while p2 $7^{\mathrm{kip} 1}$ was apparent in both the cytoplasm and nucleus (Fig. 4C). In contrast, both proteins were predominantly located in the nucleus after D-allose exposure. Together with the immunoprecipitation results, it was suggested that D-allose may cause $\mathrm{p} 27^{\mathrm{kipl}}$ stabilization by restricting the protein to nuclei, possibly through competitive inhibition of the binding of p27 $7^{\mathrm{kip} 1}$ and jab1 by TXNIP. In addition, transfer of TXNIP to nuclei would clearly facilitate direct interaction with $\mathrm{p} 27^{\mathrm{kip} 1}$ and contribute to its stabilization.

In conclusion, our study generated strong evidence that D-allose may inhibit the growth of cancer cells by specific TXNIP induction and subsequent $\mathrm{p} 27^{\mathrm{kip} 1}$ protein stabilization, without exerting appreciable effects on normal cells. D-allose may thus be useful as a novel anticancer drug, providing a new strategy for therapy or prevention in pre-cancerous patients.

\section{Acknowledgements}

This work was supported by a research grant from the Cooperative Link of Unique Science and Technology for Economy Revitalization (CLUSTER) Project of Japan.

\section{References}

1. Izumori K: Bioproduction strategies for rare hexose sugars. Naturwissenschften 89: 120-24, 2002.

2. Murata A, Sekiya K, Watanabe Y, Yamaguchi F, Hatano N, Izumori $\mathrm{K}$ and Tokuda M: A novel inhibitory effect of D-allose on production of reactive oxygen species from neutrophils. J Biosci Bioeng 96: 89-91, 2003.

3. Hossain MA, Wakabayashi H, Izuishi K, Okano K, Yachida S, Tokuda M, Izumori K and Maeta H: Improved microcirculatory effect of D-allose on hepatic ischemia reperfusion following partial hepatectomy in cirrhotic rat liver. J Biosci Bioeng 101: 369-371, 2006.

4. Sui L, Dong Y, Watanabe Y, Yamaguchi F, Hatano N, Izumori $\mathrm{K}$ and Tokuda $\mathrm{M}$ : Growth inhibitory effect of D-allose on human ovarian carcinoma cells in vitro. Anticancer Res 25: 2639-2644, 2005.

5. Sui L, Dong Y, Watanabe Y, Yamaguchi F, Hatano N, Tsukamoto I, Izumori K and Tokuda M: The inhibitory effect and possible mechanisms of D-allose on cancer cell proliferation. Int J Oncol 27: 907-912, 2005.

6. Ishida TK, Tojo T, Aoki T, Kobayashi N, Ohishi T, Watanabe T, Yamamoto T and Inoue J: TRAF5, a novel tumor necrosis factor receptor-associated factor family protein, mediates CD40 signaling. Proc Natl Acad Sci 93: 9437-9442, 1996.

7. Sharov AA, Dudekula DB and Ko MS: A web-based tool for principal component and significance analysis of microarray data. Bioinformatics 21: 2548-2549, 2005.

8. Benjamini Y and Hochberg Y: Controlling the false discovery rate - a practical and powerful approach to multiple testing. $\mathrm{J}$ R Stat Soc B 57: 289-300, 1995.

9. Dennis G, Sherman BT, Hosack DA, Yang J, Gao W, Lane HC and Lempicki RA: DAVID: Database for annotation, visualization and integrated discovery. Genome Biol 4: P3, 2003. 
10. Han SH, Jeon JH, Ju HR, Jung U, Kim KY, Yoo HS, Lee YH, Song KS, Hwang HM, Na YS, Yang Y, Lee KN and Choi I: VDUP1 up-regulated by TGF-beta1 and 1,25-dihydorxyvitamin D3 inhibits tumor cell growth by blocking cell-cycle progression. Oncogene 22: 4035-4046, 2003.

11. Ohta S, Lai EW, Pang AL, Brouwers FM, Chan WY, Eisenhofer G, Krijger R, Ksinantova L, Breza J, Blazicek P, Kvetnansky R, Wesley RA and Pacak K: Down-regulation of metastasis suppressor genes in malignant phochromocytoma. Int J Cancer 114: 139-153, 2005.

12. Bloom J and Cross FR: Multiple levels of cyclin specificity in cell-cycle control. Nat Rev Mol Cell Biol 8: 149-160, 2007.

13. Malumbres $\mathrm{M}$ and Barbacid $\mathrm{M}$ : Cell cycle kinases in cancer. Curr Opin Genet Dev 17: 60-65, 2007.

14. Sheer CJ and Roberts JM: CDK inhibitors: positive and negative regulators of G1-phase progression. Genes Dev 13: 1501-1512, 1999.

15. Chen $\mathrm{K}$ and De Luca HF: Isolation and characterization of a novel cDNA from HL-60 cells treated with 1,25-dihydroxyvitamin D-3. Biochim Biophys Acta 1219: 26-32, 1994.

16. Chung JW, Jeon JH, Yoon SR and Choi I: Vitamin D3 upregulated protein 1 (VDUP1) is a regulator for redox signaling and stress-mediated diseases. J Dermatol 33: 662-669, 2006.

17. Ikarashi M, Takahashi Y, Ishii Y, Nagata T, Asai S and Ishikawa K: Vitamin D3 up-regulated protein 1 (VDUP1) expression in gastrointestinal cancer and its relation to stage of disease. Anticancer Res 22: 4045-4048, 2002.

18. Escrich E, Moral R, García G, Costa I, Sánchez JA and Solanas M: Identification of novel differentially expressed genes by the effect of a high-fat n- 6 diet in experimental breast cancer. Mol Carcinog 40: 73-78, 2004.

19. Sheth SS, Bodnar JS, Ghazalpour A, Thipphavong CK, Tsutsumi S, Tward AD, Demant P, Kodama T, Aburatani H and Lusis AJ: Hepatocellular carcinoma in Txnip-deficient mice. Oncogene 25: 3528-3536, 2006.
20. Minn AH, Hafele C and Shalev A: Thioredoxin-interacting protein is stimulated by glucose through a carbohydrate response element and induces B-cell apoptosis. Endocrinology 146: 2397-2405, 2005.

21. Minn AH, Couto FM and Shalev A: Metabolism-independent sugar effects on gene transcription: The role of 3-O-methylglucose. Biochemistry 45: 11047-11051, 2006.

22. Astier AL, Xu R, Svoboda M, Hinds E, Munoz O, Beaumont R, Crean CD, Gabig T and Freedman AS: Temporal gene expression profile of human precursor B leukemia cells induced by adhesion receptor: identification of pathways regulating B-cell survival. Neoplasia 101: 1118-1127, 2003.

23. Tomoda K, Kubota Y, Arata Y, Mori S, Maeda M, Tanaka T, Yoshida M, Yoneda-Kato N and Kato JY: The cytoplasmic shuttling and subsequent degradation of p27kip1 mediated by jab1/CSN5 and the COP9 signalosome complex. J Biol Chem 277: 2302-2310, 2002.

24. Chiarle R, Budel LM, Skolnik J, Frizzera G, Chilosi M, Corato A, Pizzolo G, Magidson J, Montagnoli A, Pagano M, Maes B, De Wolf-Peeters C and Inghirami G: Increased proteasome degradation of cyclin-dependent kinase inhibitor p27 is associated with a decreased overall survival in mantle cell lymphoma. Blood 95: 619-626, 2000.

25. Tomoda K, Kubota Y and Kato J: Degradation of the cyclindependent-kinas inhibitor p27kip1 is instigated by jab1. Nature 398: 160-165, 1999

26. Claret FX, Hibi M, Dhut S, Toda T and Karin M: A new group of conserved co-activators that increase the specificity of AP-1 transcription factors. Nature 383: 453-457, 1996.

27. Jeon JH, Lee KN, Hwang CY, Kwon KS, You KH and Choi I: Tumor suppressor VDUP1 increases p27(kip1) stability by inhibiting JAB1. Cancer Res 65: 4485-4489, 2005. 